\title{
Research Paper: The Rate and Pattern of Disclosing Medical Errors in Iranian Physicians and Healthcare Staff
}

\author{
Davood Soroosh ${ }^{1}$ (D), Alireza Abadi², Mohammad Nematshahi ${ }^{3}$ (D)
}

1. Department of Internal Medicine, School of Medicine, Forensic Medicine, Sabzevar University of Medical Sciences, Sabzevar, Iran

2. Student Research Committee, Sabzevar University of Medical Sciences, Sabzevar, Iran.

3. Department of Anesthesiology, School of Medicine, Sabzevar University of Medical Science, Sabzevar, Iran.

$\begin{aligned} & \text { Use yourdevice toscan } \\ & \text { and read the article online }\end{aligned}$
attation: Soroosh D, Abadi A, Nematshahi M. The Rate and Pattern of Disclosing Medical Errors in Iranian Physicians
and Healthcare Staff. International Journal of Medical Toxicology and Forensic Medicine. 2020; 10(3):28202. https://doi.
org/10.32598/ijmtfm.v10i3.28202
doi https://doi.org/10.32598/ijmtfm.v10i3.28202

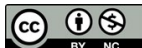

Article info:

Received: 13 Dec 2019

First Revision: 15 Dec 2019

Accepted: 01 Jul 2020

Published: 12 Oct 2020

\section{ABSTRACT}

Background: Ethics is of great significance in the medical community, i.e., because of the importance of this profession. How a physician manages a medical error, regardless of its cause, is among the major issues of medical ethics. Given the nature of the medical profession, medical malpractice may occur at any time during treatment. Medical malpractice is frequent in Iran and other countries.

Methods: The present cross-sectional study was conducted using a researcher-made checklist. The study participants attended legal medicine training and refresher courses in Mashhad and Sabzevar Cities, Iran, from June 2012 to June 2017.

Results: During five years, 1537 cases were enrolled in the study. Most of the study participants were female $(\mathrm{n}=832,52.89 \%)$, with a Mean $\pm \mathrm{SD}$ age of $32.3 \pm 3.4$ years. All study participants, except for $25(1.58 \%)$ subjects answered "I do not disclose the malpractice" to the question "would you disclose your medical malpractice with treatable harm to the patient, while he/she gets hurt by not revealing the malpractice?"; the rest [1463 (92.94\%) individuals] answered "I disclose the malpractice, but I do not mention that the harm is due to malpractice, and 85 (5.40\%) participants answered, "I disclose the malpractice to the patient and mention that the harm is due to malpractice and it could be cured".

Conclusion: The study findings suggested that the majority of study participants did not tend to disclose their malpractice to patients and their families. less of its origin $[2,3]$. An issue that may arise for physicians and healthcare workers during treatment is being accused of medical malpractice by patients [4]. Medical malpractice is any act by physicians and medical staff during a patient's treatment that deviates from accepted norms in the medical profession and damages the patient

* Corresponding Author:

Mohammad Nematshahi, MD.

Address: Department of Anesthesiology, School of Medicine, Sabzevar University of Medical Science, Sabzevar, Iran.

Tel: +98 (915) 1737407

E-mail:nematshahim@medsab.ac.ir 
[5]. The increase in the number of medical complaints is a global phenomenon; however, its rate and type vary in different countries [6].

According to a previous study, 7 million cases of medical malpractice occur annually worldwide [7]. The major fraction of reported cases could be because physicians and healthcare workers have inappropriate communication skills in response to medical errors [8]. Furthermore, physicians and healthcare workers are afraid of reputation damage $[9,10]$. This study aimed at determining the rate of disclosing medical errors and malpractices in physicians and healthcare workers in eastern medical centers, in Iran.

\section{Materials and Methods}

This cross-sectional study was conducted on medical and healthcare staff, as well as midwiferies and nursing students. The study participants attended legal medicine training and refresher courses in Mashhad and Sabzevar Cities, Iran, during the study period. At the end of each research course, a questionnaire was distributed to each study participant. The questionnaire contained some demographic and related items. The gathered data were analyzed by SPSS. All the continuous and categorical data were summarized as Mean $\pm \mathrm{SD}$ as well as frequency (percentage), respectively.

\section{Results}

The study population was 160 individuals who were recruited within 5 years. In total, 27 out of 1600 participants were excluded from the study due to providing incomplete questionnaires. Of the investigated 1537 individuals, 741 (47.10\%) were male and 832 (52.89\%) were female, with the Mean \pm SD age of $32.3 \pm 3.4$ years. Of total participants, 125 (7.94\%) individuals tended to disclose the medical malpractice to the patient's family, in the event of the patient's death, and 1448 (92.05\%) were not willing to do so. Accordingly, in the former group, 41 (32.8\%) individuals were male and 84 (67.2\%) were female. The relevant data are presented based on the study subjects' age and educational level in Table 1.

Of 1573 participants, 52 (3.30\%) individuals answered "yes" to the question "would you disclose your medical malpractice without serious harm that improves without treatment to the patients and their family?"; and 1521 (96.69\%) individuals answered "no" to the same question. Out of 52 participants with a positive answer, $9(17.30 \%)$ were male and 43 (82.69\%) were female (Table 2).

Table 1. The participant's data concerning disclosing the death of patients to their family when medical malpractice leading to death

\begin{tabular}{|c|c|c|}
\hline & & No. (\%) \\
\hline \multirow{5}{*}{ Age (y) } & $<20$ & $45(18)$ \\
\hline & $20-30$ & $37(7.48)$ \\
\hline & $30-40$ & $32(6.63)$ \\
\hline & $40-50$ & $9(3.39)$ \\
\hline & $>50$ & $2(2.43)$ \\
\hline \multirow{9}{*}{ Educational level } & BS in Nursing & $32(7.11)$ \\
\hline & MSc in Nursing & $3(3.33)$ \\
\hline & General practitioner & $24(7.74)$ \\
\hline & Specialist & $7(3.46)$ \\
\hline & & \\
\hline & BS in Midwifery & $3(4)$ \\
\hline & Midwifery student & $6(26.08)$ \\
\hline & BA student in Nursing & $21(12.72)$ \\
\hline & Medical student & $29(11.24)$ \\
\hline
\end{tabular}


Table 2. The participant's data concerning disclosing the medical malpractice without serious harm to the patient who could improve without treatment

\begin{tabular}{|c|c|c|}
\hline \multicolumn{2}{|c|}{ Variables } & \multirow{2}{*}{\begin{tabular}{|l} 
No. (\%) \\
$22(8.8)$
\end{tabular}} \\
\hline \multirow{5}{*}{ Age (y) } & $<20$ & \\
\hline & $20-30$ & $24(4.85)$ \\
\hline & $30-40$ & $3(0.62)$ \\
\hline & $40-50$ & $1(0.37)$ \\
\hline & $>50$ & $2(2.43)$ \\
\hline \multirow{9}{*}{ Educational I } & BS in Nursing & $6(1.33)$ \\
\hline & MSc in Nursing & $1(1.11)$ \\
\hline & General practitioner & $5(1.61)$ \\
\hline & Specialist & $6(2.97)$ \\
\hline & & \\
\hline & BS in Midwifery & $0(0)$ \\
\hline & Midwifery student & $2(8.69)$ \\
\hline & BA student in Nursing & 15 (9.09) \\
\hline & Medical student & $17(6.58)$ \\
\hline
\end{tabular}

Table 3. The participant's data concerning disclosing medical malpractice resulting in untreatable serious harm to the patient

\begin{tabular}{|c|c|c|}
\hline & & No. (\%) \\
\hline \multirow{5}{*}{ Age (y) } & $<20$ & $35(14)$ \\
\hline & $20-30$ & 79 (15.99) \\
\hline & $30-40$ & $36(7.46)$ \\
\hline & $40-50$ & $18(6.79)$ \\
\hline & $>50$ & $3(3.65)$ \\
\hline \multirow{8}{*}{ Educational level } & BS in Nursing & $20(4.44)$ \\
\hline & MSc in Nursing & $6(6.66)$ \\
\hline & General practitioner & 35 (11.29) \\
\hline & Specialist & $18(8.91)$ \\
\hline & BS in Midwifery & $9(12)$ \\
\hline & Midwifery student & 4 (17.39) \\
\hline & BA student in Nursing & $39(23.63)$ \\
\hline & Medical student & $40(15.50)$ \\
\hline
\end{tabular}


Table 4. The participant's data concerning not disclosing medical malpractice harms to the patient unaware of it

\begin{tabular}{|c|c|c|}
\hline \multicolumn{2}{|c|}{ Variables } & \multirow{2}{*}{$\begin{array}{c}\text { No. (\%) } \\
3(1.2)\end{array}$} \\
\hline \multirow{5}{*}{ Age (y) } & $<20$ & \\
\hline & $20-30$ & $5(1.01)$ \\
\hline & $30-40$ & $10(2.07)$ \\
\hline & $40-50$ & $5(1.88)$ \\
\hline & $>50$ & $2(2.43)$ \\
\hline \multirow{9}{*}{ Educational I } & BS in Nursing & $9(2)$ \\
\hline & MSc in Nursing & $4(4.44)$ \\
\hline & General practitioner & $4(1.29)$ \\
\hline & Specialist & $2(0.99)$ \\
\hline & & \\
\hline & BS in Midwifery & $3(4)$ \\
\hline & Midwifery student & $0(0)$ \\
\hline & BA student in Nursing & $2(1.21)$ \\
\hline & Medical student & $1(0.38)$ \\
\hline
\end{tabular}

Table 5. The participant's data concerning disclosing the medical malpractice with a treatable harmed patient without mentioning that the harm was due to their malpractice

\begin{tabular}{|c|c|c|}
\hline & & No. (\%) \\
\hline \multirow{5}{*}{ Age (y) } & $<20$ & $235(16.06)$ \\
\hline & $20-30$ & $459(31.37)$ \\
\hline & $30-40$ & $443(30.28)$ \\
\hline & $40-50$ & $251(17.15)$ \\
\hline & $>50$ & $75(5.12)$ \\
\hline \multirow{9}{*}{ Educational level } & BS in Nursing & $426(29.11)$ \\
\hline & MSc in Nursing & $83(5.67)$ \\
\hline & General practitioner & $295(20.16)$ \\
\hline & Specialist & $188(12.85)$ \\
\hline & & \\
\hline & BS in Midwifery & $67(4.57)$ \\
\hline & Midwifery student & $21(1.43)$ \\
\hline & BA student in Nursing & 146 (9.97) \\
\hline & Medical student & $237(16.19)$ \\
\hline
\end{tabular}


Table 6. The participant's data concerning disclosing the medical malpractice with a treatable harmed patient and mentioning that the harm was due to their malpractice

\begin{tabular}{|c|c|c|}
\hline \multicolumn{2}{|c|}{ Variables } & \multirow{2}{*}{$\frac{\text { No. (\%) }}{12(4.8)}$} \\
\hline \multirow{5}{*}{ Age (y) } & $<20$ & \\
\hline & $20-30$ & $30(6.07)$ \\
\hline & $30-40$ & $29(6.01)$ \\
\hline & $40-50$ & $9(3.39)$ \\
\hline & $>50$ & $5(6.09)$ \\
\hline \multirow{9}{*}{ Educational I } & BS in Nursing & $15(3.33)$ \\
\hline & MSc in Nursing & $3(3.33)$ \\
\hline & General practitioner & $11(3.54)$ \\
\hline & Specialist & $12(5.94)$ \\
\hline & & \\
\hline & BS in Midwifery & $5(6.66)$ \\
\hline & Midwifery student & $2(8.69)$ \\
\hline & BA student in Nursing & $17(10.33)$ \\
\hline & Medical student & $20(7.751)$ \\
\hline
\end{tabular}

In total, $171(10.87 \%)$ and $1402(89.12 \%)$ answered of the study subjects respectively answered "yes" and "no" to the question "Would you disclose medical malpractice with serious untreatable harm to the patient, i.e., not immediately becomes aware of it?". Of the respondents with "yes" answers, 49 (28.65\%) individuals were male and $122(71.34 \%)$ were female (Table 3$)$.

Overall, 25 (1.58\%) individuals answered: "we do not disclose the malpractice" to the question "would you disclose medical malpractice with treatable harm to the patient, where s/he gets hurt if not revealing the malpractice", and 1463 (92.94\%) answered "I disclose the malpractice, but do not mention that the harm was due to my malpractice; $85(5.40 \%)$ participants answered "I disclose the malpractice to the patient and mention that the harm was due to our malpractice and it could be cured. The related data are presented in Tables 4 to 6 , concerning the study subjects' age and educational level.

\section{Discussion}

Specializing in medical affairs and financial and social problems has reduced the proper physician-patient communications. In the last decades, raising patients' awareness of their rights and enhancing medical information in the community have been the causes of the growing trend in medical complaints [11]. International reports are available on the frequency of complaints from medical practitioners in different countries. These data suggest that despite significant scientific advances and the presence of modern technology in diagnostic and therapeutic areas, an upward trend have been observed concerning complaints [12-14]. In medical practice, some adverse outcomes are inevitable. This is due to the nature of an underlying illness, the changes in response to the treatment, and the inaccurate diagnosis of the disease [15]. Despite the highest efforts of physicians and healthcare staff, medical errors occur [16].

Medical malpractice by physicians and healthcare workers is among the most essential healthcare issues [17]. By definition, medical malpractice is a treatment, i.e., not as per accepted medical standards that results in death or a defect to the patient [18]. Medical malpractice has various types, including indifference, carelessness, and the lack of skills, i.e., fully-explained by Abdolrauof Adibzadeh and associates [18]. Medical malpractice claimed by patients is among the issues that could be encountered by physicians and healthcare workers during treatment. Annually, 7 million cases of medical malpractices are registered worldwide [19]; this rate highlights 
the significance of this problem. The physicians and healthcare personnel must admit their medical malpractice, as well as the way to report it.

Our results suggested that the most frequent age group disclosing medical malpractice to the patient's family resulting in the patient's death was $<25$ years $(18 \%)$. Moreover, the least report rate in this regard belonged to the $>50$-year-olds $(2.43 \%)$. In terms of educational level, the highest and lowest medical malpractice disclosure rates belonged to the midwifery students $(26.08 \%)$ and educated nurses (7.11\%), respectively. Dae Jong Song et al. highlighted the importance of appropriate communication between the patients and healthcare personnel; a group that approached appropriately and apologized to the patients for malpractice experienced fewer patient complaints [19].

Mohammad Reza Haghshenas et al. found that the lowest frequency of complaints and malpractices was related to the healthcare centers affiliated to the social security organization. This could be due to the free services provided to the covered population [11]. Our findings indicated that a small percentage of the explored general and specialized physicians tended to admit their medical malpractices. This result could be attributed to the improper insurance and treatment services provided to them.

\section{Conclusion}

The present study revealed that the majority of study participants did not tend to disclose their medical malpractice to the patients and their families. Our study and previous literature suggested that the malpractice could be due to low importance of the medical ethics perceived by the practitioners; their indifference towards them; religious doctrine among the healthcare staff; inappropriate cultural context for disclosing medical errors, an improper support system for the healthcare staff, and to some extent, supposing the physicians and healthcare personnel to financially abuse patients.

\section{Ethical Considerations}

\section{Compliance with ethical guidelines}

The protocol of research was approved by Sabzevar University of Medical Science.

\section{Funding}

This research did not receive any grant from funding agencies in the public, commercial, or non-profit sectors.

\section{Authors' contributions}

Methodology: Mohammad Nematshahi; Software, writing -original draft preparation, visualization, formal analysis, investigation, validation: Alireza Abadi; Conceptualization, resources, writing - review \& editing, project administration, funding acquisition, supervision: Davood Soroosh, Mohammad Nematshahi; Data Curation: All authors.

\section{Conflict of interest}

The authors declared no conflicts of interest.

\section{Acknowledgements}

The authors would like to thank to the Clinical Research Development Unit of Vasei Hospital at the Sabzevar University of Medical Sciences for their contribution to this research.

\section{References}

[1] Khani Jazani J. [Medical ethics philosophy (Persian)]. Journal of Diabetes \& Metabolic Disorders. 2007; 7(24):47-52.

[2] Hemmati Moghaddam A. Paradigm instability in medicine: Introducing Ludwik Fleck's views. Kheradname Hamshahri. $2004 ; 32$.

[3] Bastani M, Hejazi A, Zarenejad M, Shahriary S, Sahmeddini MA. Malpractice cases of anesthesiology leading to death or impairment referring to Shiraz Forensic Medicine Commissions during 2006-2011. Razi Journal of Medical Sciences (RJMS). 2014; 21(5):61-7.

[4] Gheshlaghi F, Kazemifar A. Preventing malpractice: the Coactive solution. $1^{\text {st }}$ ed. Isfahan: Farhang-e-Mardom Publication; 2001.

[5] Kwon JW, Park BY, Kang SR, Hong SE. Analysis of the legal effect of settlement agreements prepared in medical litigation following plastic surgery in Korea. Archives of Plastic Surgery. 2017; 44(4):283-92. [DOI:10.5999/aps.2017.44.4.283] [PMID] [PMCID]

[6] Khavanin Zadeh M, Gholipour F. A survey on faults and related complaints in laparoscopic surgery between 2003 and 2007 registered at Tehran Medical Legal Center. Journal of Medical Council of I.R.I. 2013; 31(1):42-4.

[7] WHO. The second global patient safety challenge: Safe surgery saves lives. WHO Patient Safety; 2008.

[8] Donaldson MS, Corrigan JM, Kohn LT. To err is human: Building a safer health system. National Academies Press; 2000.

[9] Berlin L. Will saying "I'm sorry" prevent a malpractice lawsuit? AJR Am J Roentgenol. 2006; 187(1):10-5. [DOI:10.2214/ AJR.06.0110] [PMID] 
[10] Itoh K, Andersen HB. Patient reactions to staff apology after adverse event and changes of their views in four year interval. Human Error, Safety, and Systems Development: Springer. 2010; 5962: 28-43. [DOI:10.1007/978-3-642-11750-3_3]

[11] Haghshenas MR, Vahidshahi K, Amiri A, Rezaee M, Rahmani N, Pourhossen M, et al. Study the frequency of malpractice lawsuits referred to forensic medicine department and medical council, Sari, 2006-2011. Journal of Mazandaran University of Medical Sciences. 2012; 21(6):253-60.

[12] Nobakht A, Zali M, Mahdavi M, Nourozi A. Causes of patient complaints, physician referred to the Medical Council of Tehran. Journal of Medical Council of Iran. 2000; 18(4):295-303.

[13] Rafizadeh Tabai Zavareh SM, Haj Manoochehri R, Nasaji Zavareh M. [The prevalence of malpractice complaints referred to the Commission from 2003 to 2005 (Persian)]. Tehran Legal Medicine Center. 2007; 13(3):152-7.

[14] Sadr SSh, Ghadyani MH, Bagher Zadeh AA. [Assessment of records of complaints from medical malpractice in the field of orthopedic, in the coroner's Office of Forensic Medicine, province of Tehran, during 1988 to 2003 (Persian)]. HBI Journals. 2007; 13(2):78-86.

[15] Kim JE, Weber P, Szabo A. Medical malpractice claims related to cataract surgery complicated by retained lens fragments (An American Ophthalmological Society Thesis). Transactions of the American Ophthalmological Society. 2012; 110:94-116. [PMID] [PMCID]

[16] Levinson W, Gallagher TH. Disclosing medical errors to patients: A status report in 2007. CMAJ: Canadian Medical Association Journal. 2007; 177(3):265-7. [DOI:10.1503/ cmaj.061413] [PMID]

[17] Mrayyan MT, Shishani K, Al-Faouri I. Rate, causes and reporting of medication errors in Jordan: Nurses' perspectives. Journal of Nursing Management. 2007; 15(6):659-70. [DOI:10.1111/j.1365-2834.2007.00724.x] [PMID]

[18] Adibzadeh A, Ghadi Pasha M, Pour Amiri A, Nakhaei N, Samadi Rad B, Bastani M. A study on medical malpractices ending to death and disability referred to Kerman Medical Council's Medical Malpractices Commissions. Iranian Journal of Medical Law. 2012; 6(2):141-54.

[19] Song DJ, Choi JW, Kim K, Kim MS, Moon JM. Quasi-experiment study on effectiveness evaluation of health communication strategies. Journal of Korean Medical Science. 2016; 31(7):102736. [DOI:10.3346/jkms.2016.31.7.1027] [PMID] [PMCID] 
This Page Intentionally Left Blank 